\title{
楚科奇海和白令海网采浮游植物群聚的多元分析
}

\author{
杨清良 林更铭 \\ (国家海洋局第三海洋研究所,厦门 361005)
}

摘 要 根据 1999 年夏季 (7 8 月) 我国首次北极科学考察期间 雪龙” 号考察船在楚科奇海 $\left(66^{\circ} 0.3^{\prime} \sim 75^{\circ} 18.6^{\prime} \mathrm{N}\right.$, $\left.153^{\circ} 36.5^{\prime} \sim 174^{\circ} 59.5^{\prime} \mathrm{W}\right)$ 和白令海 $\left(55^{\circ} 59.8^{\prime} \sim 66^{\circ} 0.3^{\prime} \mathrm{N}, 173^{\circ} 21.1^{\prime} \mathrm{E} \sim 175^{\circ} 53.9^{\prime} \mathrm{W}\right) 49$ 个站采集的样品研究了该区 网采浮游植物的分布特征。结果显示, 两个调查区的浮游植物多样性指数和均匀度平均值几乎相等且都较低, 分 别变动在 $1.88 \sim 1.90$ 和 $0.43 \sim 0.45$ 之间。然而, 两个区存在明显的空间异质性。就丰富度和种类组成而言, 楚科 奇海的细胞密度和物种总数量远高于白令海, 前者为 $9122.56 \times 10^{4}$ cells $\mathrm{m}^{-3}$ 和 103 种, 而后者为 $161.78 \times 10^{4}$ cells $\mathrm{m}^{-3}$ 和 71 种。上述生态学指标不同站点间的变异也大。用多元分析方法对浮游植物群聚的分布异质性加以讨论。 主成分分析 (PCA) 结果表明 解析调查区浮游植物分布方差的 $33.0 \%$ 的两个最主要成分 (即主要物种变量) 分别是 北极-北方浅海群落 (泛北极群落) 和北方大洋群落的主要种群。前者包括某些圆心硅藻, 如旋链角毛藻 (Chaetoceros curvisetus)、柔弱角毛藻 ( C. debilis)、聚生角毛藻 ( C. socialis)、叉尖角毛藻 ( C. furcellatus) 等多种葟色体类角毛藻 以及冷淡劳德藻 (Lauderia glacialis)、丹麦细柱藻 (Leptocylindrus danicus)、诺登海链藻( Thalassiosira nordenskioldii) 和脆 杆链藻 (Bacteriosira fragilis) 等; 后者主要有小环毛藻 (Corethron criophilum)、平截鼻状藻 (Proboscia truncata)、无刺鼻 状藻 ( $P$. inermis) 、西氏细齿状藻 (Dentecula seminae) 和一些多色暗角毛类角毛藻, 如大西洋角毛藻 (Chaetoceros atlanticus $)$ 等。泛北极群落主要分布于楚科奇海南部和中部, 而北方大洋群落的主要分布区在白令海调查区的西南 部。通过聚类分析还辨认出 7 个包含不同群落的主要网采浮游植物分布区, 但是由于不同水系的不同程度影响， 以及极具不确定性的浮冰的位置及其物理状态(聚集、开裂和消融等) 也会在短时间内给调查区生物过程导入变异 性，从而使得这些分布区的归类复杂化，尤其在楚科奇海。

关键词 楚科奇海和白令海网采浮游植物 分布 生态学 多元分析

\section{A MULTIVARIATE ANALYSIS OF NETPHYTOPLANKTON ASSEMBLAGES IN THE CHUKCHI SEA AND BERING SEA}

\author{
YANG Qing-Liang and LIN Geng-Ming \\ ( Third Institute of Oceanography , State Oceanic Administration , Xiamen 361005 , China)
}

\begin{abstract}
Background and Aims The phytoplankton in the Arctic seas is rarely explored on a large geographic scale , particularly at the community level. The diversity , density and distribution variability of netphytoplankton assemblages were measured at 49 stations in the Chukchi Sea $\left(66^{\circ} 0.3^{\prime}-75^{\circ} 18.6^{\prime} \mathrm{N}, 153^{\circ} 36.5^{\prime}-\right.$ $\left.174^{\circ} 59.5^{\prime} \mathrm{W}\right)$ and Bering Sea $\left(55^{\circ} 59.8^{\prime}-66^{\circ} 0.3^{\prime} \mathrm{N}, 173^{\circ} 21.1^{\prime} \mathrm{E}-175^{\circ} 53.9^{\prime} \mathrm{W}\right)$ during the FCNARE (1999) cruise on the Xuelong Research Vessel of SOA , China.
\end{abstract}

Methods The diversity indices combining the data on the abundance within a species in a community into a single number were adopted to understand the state of the community. Principal component analysis (PCA) of data was applied for examing the distribution variability of netphytoplankton. Cluster analysis was used as indicative of the degree of similarity in species composition among stations to the selected species having a frequency of occurrence greater than $10 \%$ of the total samples.

Key Results Both the mean index values of phytoplankton diversity and evenness were approximately equally low at the two study areas, ranging from 1.88 to 1.90 and from 0.43 to 0.45 , respectively. However ,both the average cell density and total species numbers in the Chukchi Sea were far greater than these in the Bering Sea , reaching $9122.56 \times 10^{4}$ cells $\mathrm{m}^{-3}$ and 103 taxa in the Chukchi Sea but only $161.78 \times 10^{4}$ cells m $^{-3}$ and 71 taxa in the Bering Sea. The results of PCA indicated that the first two components (the most important species variables) explained $33.0 \%$ of the total variance in the netphytoplankton distribution in the study areas. The main populations belong to the arctic-boreal community (pan-arctic community) and boreal oceanic 
community, including some centric diatoms in the arctic-boreal community, such as Chaetoceros curvisetus , C. debilis , $C$. socialis, $C$. furcellatus etc. belonging to the Chaetoceros-Oligochromatophorus group, and Lauderia glacialis , Leptocylindrus danicus , Thalassiosira nordenskioldii and Bacteriosira fragilis etc. , as well as Corethron criophilum , Proboscia truncata , P. inermis , Dentecula seminaeandsome and some species belonging to Chaetoceros-Phaeoceros-Polychromatophorus group such as Chaetoceros atlanticus etc. in the boreal oceanic community. Seven major netphytoplankton regions containing different phytoplankton communities in two study areas were distinguished by the cluster analysis. However, the extremely dynamic physical nature of the drifting pack ice (e.g. packing, breaking up and melting) introduce short-term variability into the water conditions that no doubt affect the species composition ; hence, the groupings of the netphytoplankton in the different regions may reflect temporal conditions , particularly in the Chukchi Sea, that require repeated sampling in order to better classify the regions.

Conclusions There were strong differences in the density and taxa of the netphytoplankton between the Chukchi Sea and Bering Sea. The density and composition were highly variable among sampling sites , particularly in Chukchi Sea.

Key words Chukchi Sea and Bering Sea, Netphytoplankton , Distribution, Ecology , Multivariate analysis

对于海洋浮游植物分布的时空差异(异质性)研 究, 国内至今大多采用单变量分析技术。常见的研 究方法往往是对一定时空单位的一定物种分布趋势 分别进行描述 就基础性调查以及原始数据资料的 积累而言, 该方法所获得的成果的意义勿庸置疑。 而且在生态系统里环境胁迫的最初迹象通常出现在 种群水平上, 首先影响特别敏感的物种 (Odum, 1992) ,因而这些工作至今仍然重要。但这种传统的 种群水平上的方法毕竟是个体生态学的研究方法, 当物种对象较多或者要用于考察研究海域的整个植 物群聚的生态特点时其局限性不言而喻。多元分析 方法恰恰可同时采集大量并存的不同物种的数据信 息做综合分析, 并可在群落水平上较客观地量化单 变量技术难以分辩的浮游植物分布的变异性来源, 因此其应用领域已从陆地生态到海洋生态，从底栖 生态到浮游生态不断扩展。例如 Estrada 和 Blasco (1979)、Blasco 等(1980)以及 Matta 和 Marshall(1984) 等,曾用主成分分析方法 (PCA) 推断上升流过程与 浮游植物分布的关系。之后不少学者的研究工作也 都陆续证明多元分析技术是量化海洋浮游植物群聚 的生态学特征及其分布变异的有效手段 (Huang et al. 1988; ;uang, , 1988 ,1993)。

有关北极海浮游植物的研究在国际上已有一个 多世纪的历史。相对而言在冰情等北极极端气候较 为显著的东西伯利亚至楚科奇海一带偏少 (Cecilie \& von Quillfeldt 2003; Heimdal , 1989 ; Werner ,1977; 杨清良等,2002)。楚科奇海是北冰洋边缘海之一, 并通过白令海峡与白令海相连, 都是来自太平洋的 高温高盐海水进入北冰洋 (输送热量)的必经通道。 近年来由于发现北极海已成为对全球气候变化有显
著贡献的海域之一,这一带的海洋科考工作日趋活 跃。作为北极海生态系统初级生产者的海洋浮游植 物, 也成为北极变化的关键问题研究不可替代的重 要研究对象(陈立奇等 2003 ;王自磐, 1997)。

我国 1999 年夏季首次在北极开展科学考察。 该航次有关楚科奇海和白令海的浮游植物物种组成 和分布等已做过研究 (杨清良等,2002)。本文拟采 用多元分析方法从群落水平上进一步探讨该区浮游 植物的空间群聚异质性。

\section{1 材料和方法}

\section{1 样品和数据来源}

所用材料取自 1999 年 7 8 月我国 雪龙号”调 查船首次北极科学考察期间分别在楚科奇海 $\left(66^{\circ} 0.3^{\prime} \sim 75^{\circ} 18.6^{\prime} \mathrm{N}, 153^{\circ} 36.5^{\prime} \sim 174^{\circ} 59.5^{\prime} \mathrm{W}\right)$ 和白 令海 $\left(55^{\circ} 59.8^{\prime} \sim 66^{\circ} 0.3^{\prime} \mathrm{N}, 173^{\circ} 21.1^{\prime} \mathrm{E} \sim\right.$ $175^{\circ} 53.9^{\prime} \mathrm{W}$ ) 所布设 49 个测站 (图 1) 的样品分析数 据。植物样品用小型浮游生物网(网长 $280 \mathrm{~cm}$, 网口 $37 \mathrm{~cm}$,篮绢网孔 $0.077 \mathrm{~mm}$ ) 自底至表拖曳, 水深大于 $200 \mathrm{~m}$ 时自 $200 \mathrm{~m}$ 处始拖至水表。

\section{2 数据统计分析}

用 PRIMER 软件。

1) 物种多样性指数 $\left(H^{\prime}\right)$ 、均匀度 $(J)$ 和种类优 势度 $(D)$ 计算公式 :

$$
\begin{aligned}
& H^{\prime}=-\sum_{i=1}^{s} p_{i} \log _{2} p_{i} \quad \text { (Shannon-Weaver ,1963) } \\
& J=H^{\prime} / \log _{2} S \quad \text { (Pielous , 1969) }
\end{aligned}
$$

2) 群落的聚类分析用 Bray-Curtis 相似性距离 :

$$
B(j, k)=\frac{\sum_{i=1}^{s}\left|X_{i j}-X_{i k}\right|}{\sum_{i=1}^{s}\left|X_{i j}+X_{i k}\right|} \quad \text { (Bray-Curtis ,1957) }
$$




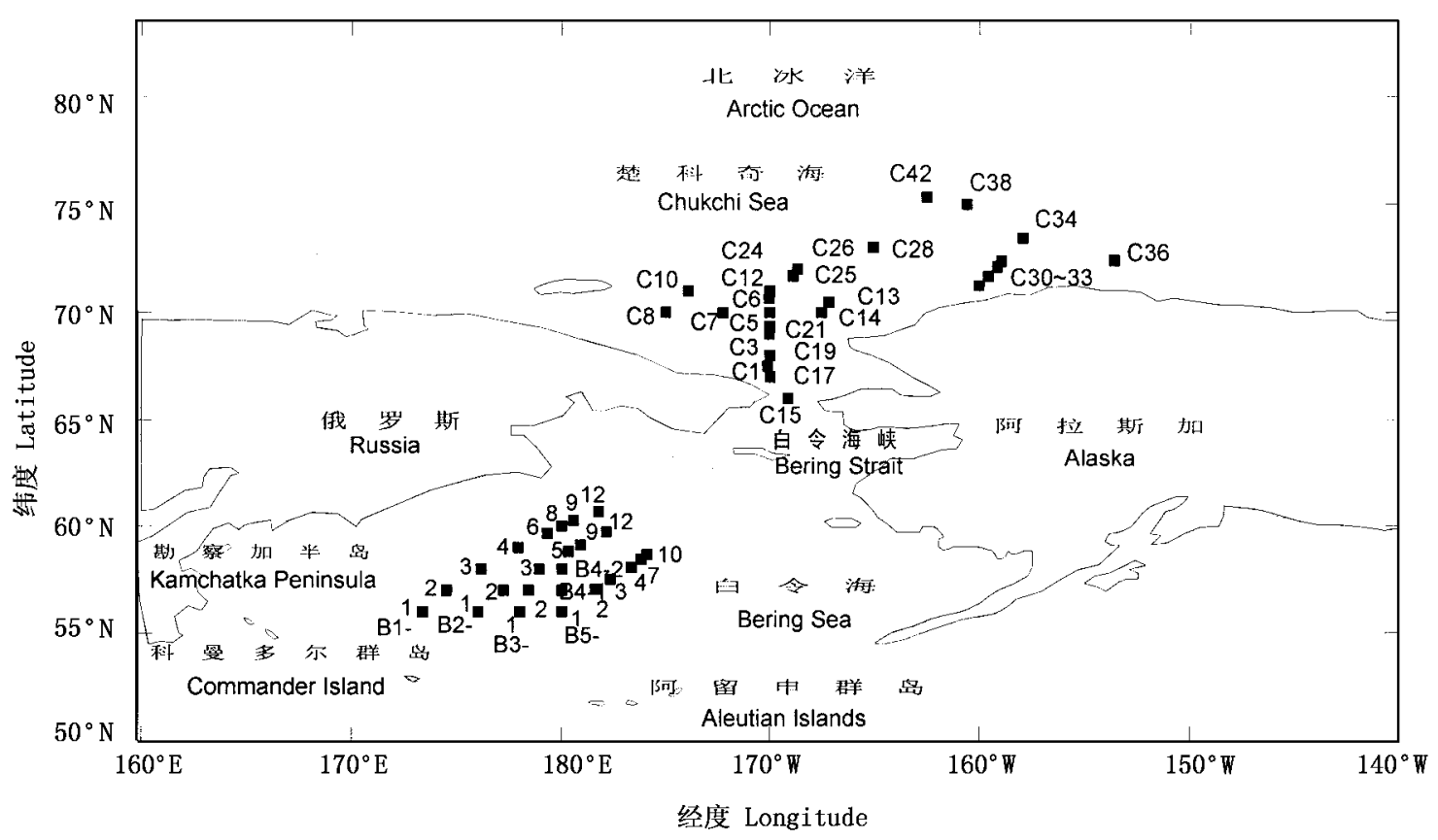

图 1 调查区浮游植物采样站 (1999 年 7 8 月)

Fig.1 Sampling stations of phytoplankton in the study areas (July - August , 1999)

式中 : $S$ 为样品中的种类数; $P i$ 为第 $i$ 种的细胞数 量与样品总细胞数量的比值; $B(j, k)$ 为第 $j$ 个和第 $k$ 个样品间的距离系数, $X_{i j}, X_{i k}$ 分别为第 $j$ 个和第 $k$ 个样品的第 $i$ 种的数据。

3)物种的篮选和数据处理 : 为简化分析数据, 避 免种类检出的偶然性及其所提供的信息意义不大， 数据分析前特挑选出现率 > $10 \%$ 的种类作为物种变 量。并在 PRIMER5.0 软件上先对物种丰富度 (细胞 密度) 作(平方根)转换和标准化等处理, 而后计算样 品间的 Bray-Curtis 相似性距离并建立相似性 矩阵。

\section{2 结果与讨论}

\section{1 浮游植物物种多样性现状}

楚科奇海和白令海通过狭窄的白令海峡连接。 在楚科奇海调查区,除了东北部北冰洋洋区少数有 关测站 (C42、C38 和 C34 等站) 水深大于 $2000 \mathrm{~m}$ 外， 普遍是水深小于 $100 \mathrm{~m}$ 的浅水浮冰区。白令海调查 区相反除了北部陆架区个别站 (B1-12、B1-9 和 B-8 等站)水深在 $165 \sim 1000 \mathrm{~m}$ 外, 其余测站都在水深达 $2000 \mathrm{~m}$ 以上的深水区(即中部白令海盆)。此外, 两 个调查区分别受到北冰洋和北太平洋不同程度的影 响。调查结果表明浮游植物分布的区间和站间都存 在较大变异。共记录网采浮游植物 121 种(含变种、
变型) ,分属于 3 门 28 属, 但两个调查区之间的共有 种仅为 13 属 49 种(表 1 ); 平均细胞密度的区间变化 范围为 $161.78 \times 10^{4} \sim 9122.56 \times 10^{4}$ cells m$^{-3}$ 站间 变化范围更大。再者, 虽然夏季是调查区浮游植物 的水华期, 优势种突出, 物种多样性指数 $\left(H^{\prime}\right)$ 和均 匀度 $(J)$ 均值偏低, 但不同测站间变化也大(表 2$)$ 。

\section{2 浮游植物数据的 PCA 分析}

根据 58 种篮选的种类 (出现率 $\geqslant 10 \%$ ) 数据进 行 PCA 分析获得 5 个重要因子, 可解析浮游植物分 布总方差的 $56.9 \%$,特别是前两个因子最为重要， 累积贡献率达 $33.0 \%$ (表 3 , 表 4)。

在 PC1 里,影响作用较大的是旋链角毛藻 (Chaetoceros curvisetus)、柔弱角毛藻 ( $C$. debilis)、圆 柱角毛藻 ( $C$. teres)、聚生角毛藻 ( $C$. socialis) 、叉尖 角毛藻 ( $C$. furcellatus)、冕胞角毛藻 ( $C$. subsecun$d u s$ ) 等多种葟色体类角毛藻 (Chaetoceros-Oligochromatophorus group), 以及冷淡劳德藻 (Lauderia glacialis)、丹麦细柱藻 ( Leptocylindrus danicus)、诺登 海链藻 (Thalassiosira nordenskioldii) 、长菱形藻 ( Nitzschia longissima)、新月筒柱藻（Cylindrotheca closterium)、柔弱圆筿藻( Coscinodiscus debilis)、脆杆链 藻 (Bacteriosira fragilis) 等圆心硅藻，具有较高的正荷 载系数,多属北极-北方群落(泛北极群落)的主要种 群。其中脆杆链藻为典型的北极种; 双尖角毛藻、聚 
表 1 楚科奇海和白令海网采浮游植物种类组成 (1999 年 7 8 月 )

Table 1 Species composition of netphytoplankton in Chukchi Sea and Bering Sea (July - August ,1999)

\begin{tabular}{|c|c|c|c|c|c|c|c|c|}
\hline \multirow{4}{*}{$\begin{array}{c}\text { 门类 } \\
\text { Phylum }\end{array}$} & \multicolumn{8}{|c|}{ 物种和属数 Numbers of species $(\mathrm{S})$ and genus $(\mathrm{G})$} \\
\hline & \multirow{2}{*}{\multicolumn{2}{|c|}{$\begin{array}{l}\text { 楚科奇海 } \\
\text { Chukchi Sea }\end{array}$}} & \multirow{2}{*}{\multicolumn{2}{|c|}{$\begin{array}{l}\text { 白令海 } \\
\text { Bering Sea }\end{array}$}} & \multirow{2}{*}{\multicolumn{2}{|c|}{$\begin{array}{c}\text { 共有种 } \\
\text { Common in both areas }\end{array}$}} & \multirow{2}{*}{\multicolumn{2}{|c|}{$\begin{array}{l}\text { 小计 } \\
\text { Total }\end{array}$}} \\
\hline & & & & & & & & \\
\hline & 属 $\mathrm{G}$ & 种 $\mathrm{S}$ & 属 $\mathrm{G}$ & 种 $\mathrm{S}$ & 属 $\mathrm{G}$ & 种 $\mathrm{S}$ & 属 $\mathrm{G}$ & 种 $\mathrm{S}$ \\
\hline 硅类门 Bacillariophyta & 28 & 94 & 20 & 57 & 11 & 44 & 32 & 104 \\
\hline 甲藻门 Pyrrophyta & 2 & 6 & 3 & 12 & 1 & 3 & 3 & 14 \\
\hline 金藻门 Chrysophyta & 3 & 3 & 2 & 2 & 1 & 2 & 3 & 3 \\
\hline 合计 Sum & 33 & 103 & 25 & 71 & 13 & 49 & 38 & 121 \\
\hline
\end{tabular}

表 2 楚科奇海和白令海网采浮游植物水平分布差异 (1999 年 $7 \sim 8$ 月)

Table 1 Variances of netphytoplankton horizontal distribution in Chukchi Sea and Bering Sea (July - August , 1999)

\begin{tabular}{cccc}
\hline \multirow{2}{*}{$\begin{array}{c}\text { 海域 } \\
\text { Area }\end{array}$} & \multicolumn{2}{c}{ 测站间变化范围 Ranging of parameters among stations } \\
\cline { 2 - 4 } & $\begin{array}{c}\text { 细胞密度 } \\
\text { Cell density }\left(10^{4} \text { cells m }{ }^{-3}\right)\end{array}$ & $\begin{array}{c}\text { 均匀度 } \\
\text { Evenness }(J)\end{array}$ & $\begin{array}{c}\text { 多样性指数 } \\
\text { Diversity index }\left(H^{\prime}\right)\end{array}$ \\
\hline 楚科奇海 Chukchi Sea & $0.16 \sim 90680.2$ & $0.07 \sim 0.87$ & $0.33 \sim 3.82$ \\
& $($ 平均 Mean $: 9122.56)$ & $($ 平均 Mean $: 0.43)$ & $($ 平均 Mean : 1.90$)$ \\
白令海 Bering Sea & $0.47 \sim 1481.28$ & $0.01 \sim 0.75$ & $0.03 \sim 3.01$ \\
& (平均 Mean :161.78) & (平均 Mean : 0.45$)$ & $($ 平均 Mean : $: 1.88)$ \\
平均 Average & 4733.61 & 0.44 & 1.89 \\
\hline
\end{tabular}

表 3 主成分分析前 5 个主成分的特征值和方差贡献率

Table 3 Eigenvalues and percent of variation explained for the first 5 components of the principal component anaysis (PCA)

\begin{tabular}{cccc}
\hline $\begin{array}{c}\text { 主成分 } \\
\text { Principal component }\end{array}$ & $\begin{array}{c}\text { 特征值 } \\
\text { Eigenvalues }\end{array}$ & $\begin{array}{c}\text { 方差贡献率 } \\
\text { Percent of variance }(\%)\end{array}$ & $\begin{array}{c}\text { 累积贡献率 } \\
\text { Cumulative variance }(\%)\end{array}$ \\
\hline 1 & 10.86 & 18.7 & 18.7 \\
2 & 8.27 & 14.3 & 33.0 \\
3 & 5.61 & 9.7 & 42.7 \\
4 & 4.32 & 7.5 & 50.1 \\
5 & 3.95 & 6.8 & 56.9 \\
\hline
\end{tabular}

生角毛藻和诺登海链藻等北极-北方近海种是本航 次楚科奇海的主要优势种(杨清良等,2002);而丹麦 细柱藻等通常是北极诸海最重要的广布种 (Heimdal ,1989 ;Melnikov ,1997; Werner ,1977)。从不同测 站的样品得分状况 (表 5) 来看 PC1 反映了泛北极群 落分布趋势的区域性和时间性。其主要分布区在楚 科奇海南部 (C21、C17 和 C19 等站)至白令海峡 (C15 站)以及中部密集浮冰区 (C28 和 C26 等站)，不仅与 东北部深水测站 (C34、C36、C38 和 C42) 以及白令 海测站不同, 甚至也和早些时候 (7 月)在楚科奇海 南部的另一些采样站 (C1、C5 和 C6 等站) 有较大差 异。同步观测数据表明, 这些差异与冰情有关。调 查期间曾在楚科奇海南部因遇到冰坝 (7 月 14 日， C14 站)而折回白令海,故同处在楚科奇海南部的相 邻有关测站采样日期可相差近 $20 \mathrm{~d}$ (表 5)。以 7 月
14 日采样的 C6 站为例, 其时表层水温为 $0.58{ }^{\circ} \mathrm{C}$ (各层平均 $-0.95{ }^{\circ} \mathrm{C}$ ) 表层盐度为 27.14 (各层平均 $31.04)$, 而相邻的 C21 站是在 $19 \mathrm{~d}$ 后采样, 表层水温 和盐度已分别达 $3.88^{\circ} \mathrm{C}$ 和 32.67 。反映了融冰期与 非融冰期间较大的物理环境差异。据研究, 北极海 海冰对藻类分布的影响除了通过其物理状态(聚集、 开裂和消融等) 外, 动态的浮冰位置也会在短时间内 (甚至是以 $\mathrm{d}$ 为单位) 给调查区生物过程增加变异性 (Heimdal ,1989 ; Melnikov ,1997)。

PC2 里荷载系数绝对值较高的种类是小环毛藻 (Corethron criophilum)、平截鼻状藻 (Proboscia trunca$t a)$ 、无刺鼻状藻 ( $P$. inermis )、钝棘根管藻半刺变种 (Rhizosolenia hebetata var. hiemalis)、西氏细齿状藻 (Dentecula seminae)、椭圆星脐藻 ( Asterolampra heptactis) 、渐尖鯺藻 (Dinophysis acuminata) 、柔弱伪菱形藻 
表 4 浮游植物特选物种主成分分析的因子荷载

Table 4 Variable loadings of selected species of phytoplankton in the principal component anaysis (PCA)

\begin{tabular}{|c|c|c|c|c|c|}
\hline \multirow{2}{*}{$\begin{array}{c}\text { 变量 } \\
\text { Variable }\end{array}$} & \multicolumn{5}{|c|}{ 主成分 Principal component } \\
\hline & PC1 & $\mathrm{PC} 2$ & $\mathrm{PC} 3$ & PC4 & PC5 \\
\hline 椭圆星脐藻 Asterolampra heptactis & -0.025 & 0.333 & -0.043 & 0.008 & 0.069 \\
\hline 脆杆链藻 Bacteriosira fragilis & 0.169 & -0.006 & 0.011 & -0.198 & 0.130 \\
\hline 大西洋角毛藻 Chaetoceros atlanticus & -0.030 & 0.339 & -0.031 & 0.001 & 0.034 \\
\hline 北方角毛藻 $C$. borealis & 0.057 & 0.003 & 0.082 & -0.135 & -0.286 \\
\hline 扁面角毛藻 $C$. compressus & 0.103 & -0.019 & -0.100 & 0.173 & 0.033 \\
\hline 曲刺角毛藻 C. concavicornis & 0.049 & 0.067 & 0.116 & -0.162 & -0.384 \\
\hline 缢缩角毛藻 $C$. constrictus & 0.024 & -0.033 & -0.160 & 0.024 & 0.075 \\
\hline 旋链角毛藻 $C$. curvisetus & 0.269 & 0.030 & 0.117 & 0.033 & 0.102 \\
\hline 柔弱角毛藻 C. debilis & 0.263 & 0.028 & 0.141 & 0.042 & 0.112 \\
\hline 并基角毛藻 $C$. decipiens & 0.236 & 0.025 & 0.060 & 0.248 & -0.115 \\
\hline 密连角毛藻 $C$. densus & 0.084 & -0.007 & 0.137 & -0.193 & -0.180 \\
\hline 远距角毛藻 $C$. distans & 0.220 & 0.012 & 0.145 & -0.016 & 0.012 \\
\hline 叉尖角毛藻 C. furcellatus & 0.180 & -0.025 & -0.080 & 0.025 & -0.139 \\
\hline 聚生角毛藻 $C$. socialis & 0.199 & 0.020 & 0.153 & -0.158 & 0.211 \\
\hline 冕胞角毛藻 $C$. subsecundus & 0.172 & 0.012 & 0.084 & 0.090 & -0.213 \\
\hline 扭角毛藻 $C$. convoltus & 0.145 & 0.243 & -0.036 & 0.225 & -0.010 \\
\hline 圆柱角毛藻 $C$. teres & 0.211 & -0.009 & 0.073 & -0.024 & 0.060 \\
\hline 角毛藻 Chaetoceros sp. & 0.259 & 0.010 & -0.049 & 0.136 & -0.002 \\
\hline 小环毛藻 Corethron criophilum & -0.032 & 0.340 & -0.033 & 0.004 & 0.031 \\
\hline 星脐圆篮藻 Coscinodiscus asteromphalus & 0.064 & -0.015 & 0.017 & -0.103 & -0.158 \\
\hline 柔弱圆篮藻 $C$. debilis & 0.191 & 0.009 & -0.010 & 0.262 & -0.049 \\
\hline 偏心圆篮藻 $C$. excentricus & 0.033 & -0.041 & -0.092 & -0.014 & -0.078 \\
\hline 宽边圆篲藻 $C$. marginatus & -0.054 & -0.002 & 0.059 & 0.016 & -0.048 \\
\hline 虹彩圆篮藻 $C$. oculus-iridis & 0.202 & 0.024 & 0.010 & 0.328 & -0.060 \\
\hline 圆筛藻 Coscinodiscus sp. & 0.011 & -0.030 & -0.065 & -0.013 & -0.040 \\
\hline 新月筒柱藻 Cylindrotheca closterium & 0.198 & 0.023 & 0.188 & -0.161 & 0.191 \\
\hline 西氏细齿状藻 Dentecula seminae & -0.056 & 0.244 & 0.036 & -0.002 & -0.186 \\
\hline 翼内茧藻 Entomoneis alata ( = Amphiprora alata ) & 0.040 & 0.007 & -0.130 & -0.045 & 0.036 \\
\hline 脆杆藻 Fragilaria $\mathrm{sp}$. & 0.072 & 0 & -0.275 & -0.186 & -0.062 \\
\hline 冷淡劳德藻 Lauderia glacialis & 0.228 & -0.001 & -0.150 & 0.059 & -0.067 \\
\hline 丹麦细柱藻 Leptocylindrus danicus & 0.218 & 0.013 & -0.118 & -0.136 & -0.108 \\
\hline 舟形藻 Navicula sp. & 0.017 & 0.011 & -0.209 & -0.011 & 0.088 \\
\hline 寒带菱形藻 Nitzschia frigida & 0.030 & -0.021 & -0.048 & -0.056 & 0.015 \\
\hline 格鲁菱形藻 $N$. grunowii & 0.092 & -0.013 & -0.270 & -0.216 & -0.069 \\
\hline 长菱形藻 $N$. longissima & 0.212 & 0.019 & -0.023 & 0.310 & -0.067 \\
\hline 菱形藻 Nitzschia sp. & 0.114 & -0.037 & -0.322 & -0.111 & -0.046 \\
\hline 柔弱伪菱形藻 Pseudo-nitzschia delicatissima & 0.004 & 0.306 & -0.150 & -0.066 & 0.038 \\
\hline 尖刺伪菱形藻 P. pungens & 0.135 & 0 & -0.265 & -0.170 & -0.066 \\
\hline 成列伪菱形藻 $P$. seriata & -0.039 & 0.117 & 0.026 & -0.029 & -0.259 \\
\hline 斜纹藻 Pleurosigma sp. & 0.054 & -0.014 & -0.275 & -0.084 & 0.069 \\
\hline 翼鼻状藻 Proboscia alata & 0.150 & 0.019 & 0.220 & -0.254 & 0.157 \\
\hline 平截鼻状藻 $P$. truncata & -0.031 & 0.340 & -0.033 & 0.004 & 0.029 \\
\hline 无刺鼻状藻 P. inermis & -0.011 & 0.336 & -0.026 & -0.008 & 0.059 \\
\hline 笔尖根管藻 Rhizosolenia styliformis & 0.148 & 0.011 & 0.172 & -0.179 & -0.154 \\
\hline 刚毛根管藻 $R$. setigera & 0.084 & 0.020 & 0.168 & -0.183 & -0.083 \\
\hline 钝棘根管藻半刺变种 $R$. hebetata var. hiemalis & 0.057 & 0.221 & 0.108 & -0.143 & 0.190 \\
\hline 中胁骨条藻 Skeletonema costatum & -0.005 & -0.017 & 0.016 & 0.009 & -0.003 \\
\hline 鼓胀海链藻 Thalassiosira gravida & 0.044 & -0.025 & -0.119 & -0.065 & -0.020 \\
\hline 诺登海链藻 T. nordenskioldii & 0.216 & 0 & 0.030 & -0.151 & 0.080 \\
\hline 细弱海链藻 T. subtilis & 0.141 & -0.020 & -0.259 & -0.003 & -0.091 \\
\hline 长海毛藻 Thalassiothrix longissima & -0.031 & 0.049 & 0.023 & -0.037 & -0.027 \\
\hline 伏恩海毛藻 T. frauenfeldii & 0.041 & 0.038 & -0.120 & -0.163 & -0.006 \\
\hline 梭角藻 Ceratium fusus & -0.055 & 0.125 & 0.068 & -0.020 & -0.289 \\
\hline 线纹角藻 $C$. lineatum & -0.053 & 0.086 & 0.073 & -0.028 & -0.293 \\
\hline 弯顶角藻 $C$. longipes & -0.080 & 0.025 & 0.087 & 0.022 & -0.168 \\
\hline 渐尖鯺藻 Dinophysis acuminata & -0.029 & 0.328 & -0.042 & 0.012 & 0.078 \\
\hline 扁平原多甲藻 Protoperidinium depressum & 0.002 & -0.016 & -0.018 & 0.033 & 0.066 \\
\hline 六异刺硅鞭藻 Distephanus speculum & 0.021 & -0.026 & -0.079 & 0.003 & -0.096 \\
\hline
\end{tabular}


表 5 调查区样品的主成分得分

Table 5 Principal component scores maked fromthe samples collected in the study areas

\begin{tabular}{|c|c|c|c|c|c|c|}
\hline \multirow{2}{*}{$\begin{array}{c}\text { 样品 } \\
\text { Samples }\end{array}$} & \multicolumn{5}{|c|}{ 主成分得分 Principal component scores } & \multirow{2}{*}{$\begin{array}{c}\text { 采样日期 Sampling date } \\
\text { 月-日 Month-day }\end{array}$} \\
\hline & 1 & 2 & 3 & 4 & 5 & \\
\hline C1 & -0.136 & -0.479 & -0.071 & -0.543 & 1.233 & $7-14$ \\
\hline C5 & -0.084 & -0.867 & 0.573 & 0.153 & -0.205 & $7-14$ \\
\hline C6 & -0.833 & -0.742 & -0.206 & 0.662 & 0.449 & $7-14$ \\
\hline C7 & -0.531 & -0.942 & -2.208 & -0.097 & 0.586 & $7-15$ \\
\hline C8 & -1.420 & -0.734 & 0.373 & 0.580 & 0.647 & $7-15$ \\
\hline C10 & -0.836 & -0.711 & -0.487 & 0.398 & 0.665 & $7-16$ \\
\hline C12 & 0.881 & -0.878 & -0.652 & -0.414 & 1.241 & $7-17$ \\
\hline C13 & 2.649 & -0.793 & -1.324 & -2.413 & -1.623 & $7-18$ \\
\hline C14 & -1.367 & -0.719 & 0.523 & 0.347 & 0.553 & $7-18$ \\
\hline C15 & 15.174 & 1.393 & 0.318 & 9.667 & -1.646 & $8-3$ \\
\hline C17 & 4.996 & -0.066 & 3.036 & -1.732 & -5.940 & $8-3$ \\
\hline C19 & 1.584 & 0.065 & 4.350 & -4.339 & -3.432 & $8-3$ \\
\hline C21 & 11.518 & 1.167 & 7.191 & -6.378 & 6.055 & $8-3$ \\
\hline C24 & 1.917 & -1.416 & -1.263 & -0.491 & -2.309 & $8-4$ \\
\hline $\mathrm{C} 25$ & 1.304 & -1.048 & -1.334 & -0.920 & -0.991 & $8-4$ \\
\hline C26 & 2.991 & -0.782 & -4.809 & -1.312 & 0.905 & $8-4$ \\
\hline C28 & 5.374 & -0.011 & -10.567 & -5.526 & -1.659 & $8-5$ \\
\hline C30 & 0.269 & -0.498 & -1.263 & 0.005 & -0.601 & $8-8$ \\
\hline C31 & 0.622 & -1.201 & -3.802 & 0.910 & 0.125 & $8-8$ \\
\hline C32 & 0.301 & -0.911 & -2.821 & 0.806 & 1.866 & $8-8$ \\
\hline C33 & 0.414 & -0.859 & -0.791 & 0.904 & 1.751 & $8-9$ \\
\hline C34 & -1.497 & -0.733 & 0.417 & 0.528 & 0.637 & $8-9$ \\
\hline C36 & -1.483 & -0.733 & 0.381 & 0.521 & 0.651 & $8-10$ \\
\hline C38 & -1.487 & -0.737 & 0.406 & 0.526 & 0.665 & $8-19$ \\
\hline $\mathrm{C} 42$ & -1.485 & -0.735 & 0.414 & 0.519 & 0.645 & $8-23$ \\
\hline B1-12 & -1.325 & -0.429 & 0.278 & 0.582 & 0.613 & $7-31$ \\
\hline B1-9 & -1.389 & -0.750 & 0.362 & 0.545 & 0.590 & $7-21$ \\
\hline B1-8 & -1.352 & -0.667 & 0.341 & 0.556 & 0.563 & $7-21$ \\
\hline B1-6 & -1.533 & -0.705 & 0.475 & 0.530 & 0.621 & $7-21$ \\
\hline B1-4 & -1.562 & -0.628 & 0.495 & 0.534 & 0.513 & $7-21$ \\
\hline B1-3 & -1.422 & 0.071 & 0.862 & 0.093 & 0.929 & $7-22$ \\
\hline B1-2 & -1.79 & 18.764 & -1.718 & 0.245 & 2.070 & $7-23$ \\
\hline B1-1 & -2.755 & 4.129 & 2.421 & -0.802 & -8.038 & $7-21$ \\
\hline B2-1 & -1.871 & 0.291 & 1.409 & -0.147 & -1.371 & $7-24$ \\
\hline B3-1 & -1.572 & -0.626 & 0.506 & 0.517 & 0.430 & $7-24$ \\
\hline B5-1 & -1.904 & -0.588 & 0.952 & 0.695 & -0.303 & $7-24$ \\
\hline B5-3 & -1.528 & -0.534 & 0.901 & 0.226 & -0.035 & $7-26$ \\
\hline B5-2 & -1.508 & -0.722 & 0.439 & 0.524 & 0.602 & $7-26$ \\
\hline B4-1 & -1.729 & -0.571 & 0.757 & 0.563 & -0.078 & $7-27$ \\
\hline B3-2 & -1.549 & -0.640 & 0.494 & 0.506 & 0.446 & $7-27$ \\
\hline B2-2 & -1.910 & 1.323 & 0.784 & 0.154 & -1.066 & $7-28$ \\
\hline B2-3 & -1.601 & -0.642 & 0.576 & 0.514 & 0.308 & $7-28$ \\
\hline B4-2 & -1.733 & -0.280 & 0.747 & 0.466 & -0.119 & $7-30$ \\
\hline B2-5 & -1.484 & -0.720 & 0.411 & 0.518 & 0.663 & $7-30$ \\
\hline B2-9 & -1.487 & -0.721 & 0.410 & 0.522 & 0.661 & $7-30$ \\
\hline B2-12 & -1.484 & -0.716 & 0.410 & 0.518 & 0.657 & $7-31$ \\
\hline B5-4 & -1.334 & 0.766 & 0.331 & -1.292 & -0.067 & $7-31$ \\
\hline B5-7 & -1.491 & -0.715 & 0.408 & 0.498 & 0.638 & $8-1$ \\
\hline B5-10 & -1.523 & -0.718 & 0.564 & 0.575 & 0.508 & $8-1$ \\
\hline
\end{tabular}


(Pseudo-nitzschia delicatissima) 和一些多色暗角毛类 角毛藻 (Chaetoceros-Phaeoceros-Polychromatophorus group) 如大西洋角毛藻 (Chaetoceros atlanticus) 和扭 角毛藻 ( C. convoltus ) 等, 多属北方大洋性群落的成 员( Motoda \& Minoda ,1974;Werner,1977) ,这些种类 在白令海调查区常见,尤其是西南偶 (B1-2、B1-1、 B2-2、B2-1 等) ; 其次在白令海峡 (C15 站) 至楚科奇 海南部(C21 等站)细胞密度也高。该群落的分布可 能和经科曼多尔群岛入侵白令海的北太平洋水系的 影响有关。据研究, 温度和盐度较高的北太平洋水 进入白令海后往东和往北因混和逐渐变性(汤毓祥 等,2001)。从表层实测温度和盐度值看, B1-1、 B2-1、B3-1 等站都较高, 尤其是前两站居白令海调查 区各站之冠,分别达 $8.41^{\circ} \mathrm{C}$ 和 33.02 左右。因此该 群落虽在白令海有较广泛的分布, 但在丰度上以西 南偶测站明显较多。而在楚科奇海含该群落的种类 成分较高的区域仅限于与白令海直接相连的南部和 东部个别站。其中最具代表性的是西氏细齿状藻等 西北太平洋指标种(杨清良等,2002)，反映了北太平 洋水对调查区不同程度的影响以及楚科奇海与白令 海在一定程度上的联系。

PC3 里正荷载系数较高的主要是翼鼻状藻
( Proboscia alata)、笔尖根管藻 (Rhizosolenia styliformis)、刚毛根管藻 ( R. setigera $)$ 和新月筒柱藻等, 大多为北温带广布性外洋种,广泛分布在盐度高于 32 的白令海海盆 (尤其是西南偶) 和楚科奇海南部 测站 (C21、C19 和 C17 站) ;负荷载系数较高的主要 是菱形藻 (Nitzschia sp.) 、格鲁菱形藻 ( N. grunowi$i$ )、尖刺伪菱形藻 (Pseudo-nitzschia pungens) 、脆杆藻 (Fragilaria sp.) 、斜纹藻 (Pleurosigma sp.) 和舟形藻 ( Navicula sp.) 等小型羽纹硅藻, 主要分布于中部密 集浮冰区 (C28、C26 和 C7 等站) 以及东部浮冰区外 缘 (C31 和 C32 等站)。这些种多为北极冰藻群落的 常见种 (Heimdal , 1989 ; Horner \& Alexander,1972； Melnikov ,1997)，应与该水域浮冰的消融直接有关。

PC4 正荷载系数较高的主要是北方大洋群落里 的虹彩圆筛藻 (Coscinodiscus oculus-iridis) 和扭角毛藻 以及泛北极群落的长菱形藻、柔弱圆筱藻等种类, 从 表 5 相应的测站样品得分可知主要反映了白令海水 系和楚科奇海水系在白令海峡 (C15 站) 的交汇影 响, 负荷载系数较高的主要是翼鼻状藻、刚毛根管 藻、笔尖根管藻等两个调查区常见的广布种以及北 极-北方群落的优势种格鲁菱形藻和脆杆链藻, 则主 要反映这些种群在楚科奇海南部和中部 (C21、C28

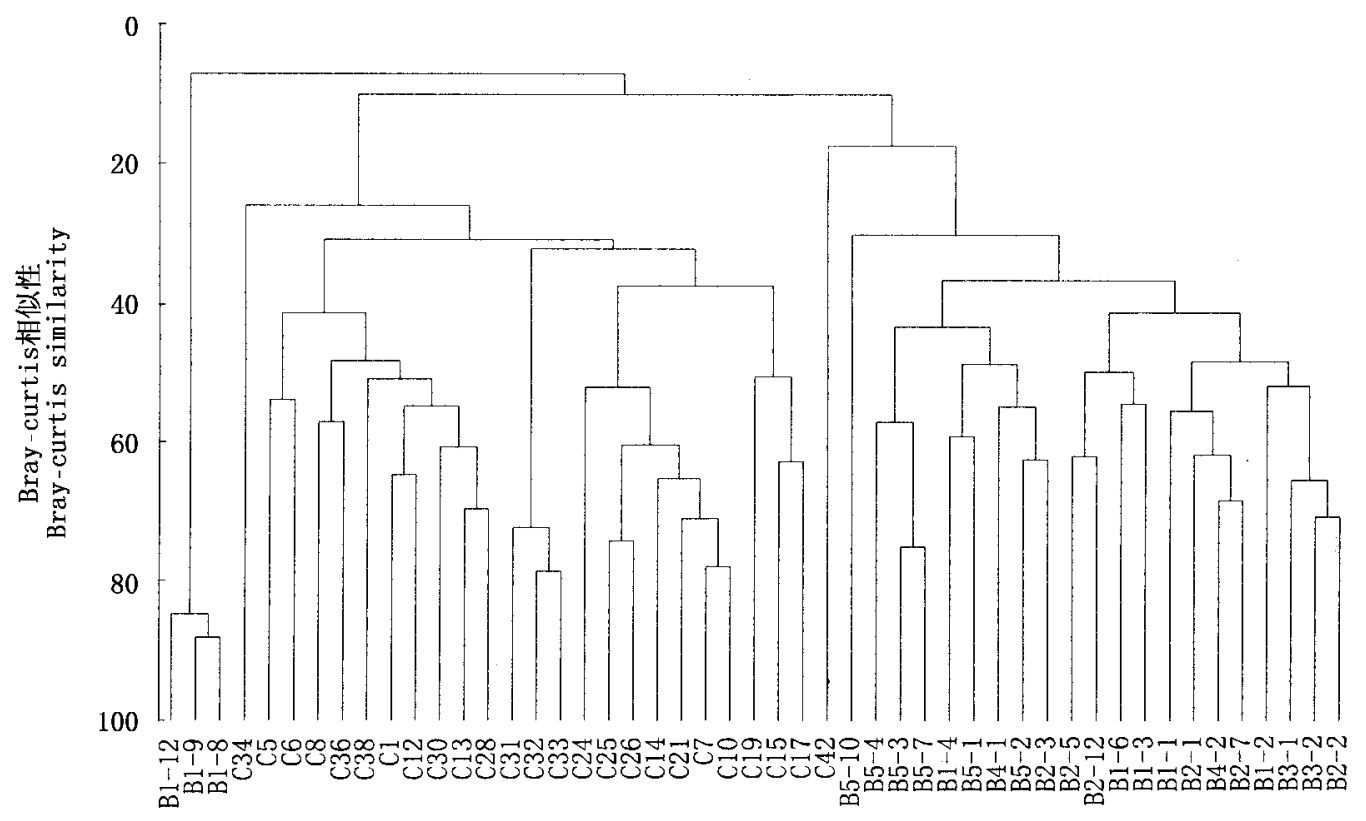

测站 Stations 
和 C19 等站)藻类水华区的细胞密度的异常激增。 PC5 里正、负荷载系数绝对值较高的分别是聚生角 毛藻、新月筒柱藻和脆杆链藻等北极-北方沿岸种、 泛北极大洋种曲刺角毛藻 (Chaetoceros concavicornis)、 北方角毛藻 ( $C$. borealis) 以及北温带大洋性种钝棘 根管藻半刺变种、线纹角藻 (Ceratium lineatum) 、梭 角藻 ( C. fusus) 、成列伪菱形藻 (Pseudo-nitzschia seri$a t a)$ 等, 分别在楚科奇海南部 (C21) 和白令海西南部 (B1-2 等站) 形成密度中心。因此 P3、P4 和 P5 分别 反映了与调查区植物块状密集分布区的形成有直接 关系的主要种群的分布特点, 同时也在一定程度上 体现了北极海同一局部海区浮游植物可具多种群落 混合聚集的生物地理学特征 (Heimdal , 1989 ;Melnikov ,1997)。

为进一步认识调查区网采浮游植物聚群的复杂 性 根据各测站种类组成的 Bray-Curtis 相似性系数 距离进行聚类分析，结果(图 2) 表明楚科奇海和白 令海 2 个相似性不高的独立群落大体可细分为 7 个 植物群聚区。除了白令海的陆架区测站 (B1-12、 B1-9、B1-8) (水深小于 $1000 \mathrm{~m}$ ) 和楚科奇海的北冰洋 深水测站 (C42 等) (水深大于 $2000 \mathrm{~m}$ ) 可独立分出 外, 位于白令海海盆 (水深大于 $2000 \mathrm{~m}$ ) 的浮游植物 测站可分为西南至中部和东侧等群聚区; 而楚科奇 海浅水浮冰大体上可分为白令海峡 (C15 站附近)、 东部(浮冰区外缘)和南部至中部(密集浮冰区)等群 聚区。但受不同水系和冰情等因素的影响，各区站 之间有交叉。有关浮游植物群落结构特点与诸多环 境因素之间内在的动力学关系, 尚需进一步深入研 究。

\section{参 考 文 献}

Blasco D, Estrada M, Jones B (1980). Relationship between the phytoplankton distribution and composition and the hydrography in the Northwest African upwelling region near Cabo Corbeiro. Deep-Sea Research, 27A, $799-821$.

Bray JR, Curtis JT (1957) . An ordination of the upland forest communities of southern Wisconsin. Ecological Monograph, 27, 325 -349 .

Cecilie H, von Quillfeldt CH (2003). Microalgae and biodiversity in polar regions. In: Iken K, Konar B eds. Proceedings of the Arctic Biodiversity Workshop: New Census of Marine Life Initiative . Alaska Sea Grant College Program, Fairbanks, Alaska, M-26, $131-149$

Chen LQ (陈立奇), Zhao JP (赵进平), Bian LG (市林根), Chen M (陈敏), Gao AG(高爱国), Chen B (陈波) (2003). Marine
Environment and Air-Sea Interaction in the Arctic Region (北极海 洋环境与海气相互作用研究). China Ocean Press, Beijing, 1 - 339. (in Chinese)

Estrada M, Blasco D (1979). Two phases of the phytoplankton community in the Baja California upwelling. Limnology and $O$ ceanography, 24, $1065-1080$.

Heimdal BR (1989). Arctic ocean phytoplankton. In: Herman Y ed. The Arctic Seas - Climatology, Oceanography, Geology, and Biology. van Nostrand Reinnold Company, New York, 193 222.

Horner RA, Alexander V (1972). Algal population in Arctic sea ice: an inverstigation of heterotrophy. Limnology and Oceanography, 17, $454-458$.

Huang R, Jan LL, Chang CH (1988). A preliminary analysis of phytoplankton variability in the western Philippine Sea. Acta Oceanographica Taiwannica, 21, 82-91.

Huang R (1988). The influence of hydrography on the distribution of phytoplankton in the southern Taiwan Strait. Estuarine, Coastal and Shelf Science, 26, 643-656.

Huang R (1993). Phytoplankton distribution in the South China Sea and Kuroshio-flowing region of Taiwan. Acta Oceanographica Taiwannica, 31, 73-82.

Matta JF, Marshall HG (1984). A multivariate analysis of phytoplankton assemblages in the western North Atlantic. Journal of Plankton Research, 6, 663-675.

Melnikov IA ( 1997). The Arctic Sea Ice Ecosystem. Gordon and Breach Science Publishers, Amstedam, the Nethelands. 67 90 .

Motoda S, Minoda T (1974). Plankton of the Bering Sea. In: Hood DW, Kelley EJ eds. Oceanography of the Bering Sea. Vail-Ballou Press, Fairbanks, Alaska, 207 - 241.

Odum EP (1992). Great ideas in ecology for the 1990s. BioScience, 42, $542-545$.

Pielous EC (1969). An Introduction to Mathematical Ecology. Wiley Interscience, New York, 1-286.

Shannon CE, Weaver W (1963). The Mathematical Theory of Communication. Illinios University Press, Urbana, Illinios, 1 125.

Tang YX (汤毓祥), Jiao YT (矫玉田), Zou EM (邹娥梅) (2001). Preliminary analysis of the hydrographic features and water masses in the Bering Sea and the Chukchi Sea. Chinese Journal of Polar Research (极地研究) , 13,57 - 68. (in Chinese with English abstract)

Wang ZP (王自磐) (1997). Marine biology process and global climatic changes in Polar Regions. Donghai Marine Science (东 海海洋) , 15(3), 29-35. (in Chinese with English abstract)

Werner D(1977). The Biology of Diatoms. Botanical Monographs Vol. 13. University of California Press, Berkeley, Califonia, 1 -498 .

Yang QL (杨清良), Lin GM (林更铭), Lin M(林茂), Lin JH (林景宏), Dai YY (戴燕玉) (2002). Species composition and distribution of phytoplankton in the Chukchi Sea and the Bering Sea. Chinese Journal of Polar Research (极地研究) , 14, 113 125. (in Chinese with English abstract) 